\title{
Spatial and temporal aggregation of albatross chick mortality events in the Falklands suggests a role for an unidentified infectious disease
}

\author{
Francesco Ventura ${ }^{1}\left(\mathbb{D} \cdot\right.$ José Pedro Granadeiro $^{1} \cdot$ Rafael Matias $^{2} \cdot$ Paulo Catry $^{3}$
}

Received: 29 April 2020 / Revised: 23 December 2020 / Accepted: 28 December 2020

(c) The Author(s), under exclusive licence to Springer-Verlag GmbH, DE part of Springer Nature 2021

\begin{abstract}
In the context of environmental change, determining the causes underpinning unusual mortality events of vertebrate species is a crucial conservation goal. This is particularly true for polar and sub-polar colonial seabirds, often immunologically naïve to new and emerging diseases. Here, we investigate the patterns of black-browed albatross (Thalassarche melanophris) chick mortality events unrelated to predation recorded between the 2004/05 and 2019/2020 breeding seasons in four colonies across the species range in the Falklands. The prevalence of these mortality events was highly variable across years, causing the death of between 3 and $40 \%$ of all chicks in the studied plots. With few exceptions, mortality was patchily distributed. Using clustering methodologies, we identified the spatio-temporal mortality clusters based on the nest locations and chick death date. Using generalised linear models and generalised additive mixed-effects models we found that chicks nearer the first mortality event were predicted to die before those in more distant nests. The probability of death increased with age and was highest for chicks close to nests where a chick had died previously. Our findings, along with the symptoms consistently exhibited by most deceased chicks in the study, strongly suggest the prevalence of a widespread infectious disease, potentially with a common aetiology, both in areas with regular and with very rare human presence. Understanding the causes driving these disease-related mortality events, which seem different from the outbreaks documented in the literature, is a conservation priority for the Falklands black-browed albatross population, which comprises over $70 \%$ of the species global population.
\end{abstract}

Keywords Albatross $\cdot$ Thalassarche melanophris $\cdot$ Chick mortality $\cdot$ Brooding $\cdot$ Cluster analysis $\cdot$ Disease

\section{Introduction}

Seabirds are top-predators playing a key role in the marine ecosystems worldwide. They are health indicators of their prey populations and of the whole food chain (Cairns 1988;

Francesco Ventura

fraventura.92@gmail.com

http://www.cesam.ua.pt

José Pedro Granadeiro

http://www.cesam.ua.pt

Paulo Catry

http://www.mare.ispa.pt

1 CESAM, Departamento de Biologia Animal, Faculdade de Ciências, Universidade de Lisboa, Campo Grande, 1749-016 Lisboa, Portugal

2 2700-256 Amadora, Portugal

3 MARE - Marine and Environmental Sciences Centre, ISPA - Instituto Universitário, Rua Jardim do Tabaco 34, 1149-041 Lisboa, Portugal
Monaghan 1996), consuming every year an overall biomass of the same order of magnitude of global fisheries (Cury et al. 2011). Of all avian groups, seabirds are among the most threatened, with $31 \%$ of all species globally threatened, a further $11 \%$ near threatened and $47 \%$ of the species showing declining population trends (Dias et al. 2019). Major threats underlying the observed declines are fishery bycatch, invasive alien species, the current and predicted effects of climate change and the outbreaks of infectious diseases (Dias et al. 2019). In fact, due to their colonial and philopatric behavioural traits, seabirds are among the animal groups most susceptible to disease and parasitic infections (Cairns 1992; Uhart et al. 2018).

Albatrosses (family Diomedeidae) are one of the most rapidly declining seabird groups. With the exception of the black-browed albatross (Thalassarche melanophris, hereafter BBA), all albatross species are currently listed as threatened or near threatened, with ongoing dramatic population declines documented in several populations (Birdlife International 2018a). The BBA is in the category of 
"Least Concern" as classified by the IUCN (Birdlife International 2018b) due to recent increases in population sizes in the Falkland Islands and in Chile. The Falkland Islands contain most of the world BBA breeding population (over $70 \%$ ), concentrated in 12 colonies (Wolfaardt 2013). BBA are long-lived and extremely philopatric birds, with pairs nesting in the same area of a given sub-colony year after year (usually re-occupying the same nest). They lay clutches of one egg per year (in the beginning of October) with the hatching period occurring during the last three weeks of December. The chick is guarded by one parent (brooding period) for 11-33 days (Catry et al. 2010), and then stays alone in the nest until fledging, which occurs at around 116 days of age (Tickell 2000).

During a longitudinal demographic study on BBA taking place on New Island, West Falklands (Catry et al. 2011), the BBA study cohort survival and breeding success were monitored since the research began in 2003/04, and nestling mortality episodes have been noted annually during the brooding period. Besides mortality events associated to predation by Falkland skuas (Catharacta antarctica antarctica) or striated caracaras (Phalcoboenus australis), across the different years a variable proportion of nestlings were found dead in the nest, in most cases still guarded by one adult. Suggestive anecdotal records during the brooding period were made a few decades before by Tickell and Pinder (1975), which described the events of chick mortality not related to predation as "virus-like infections", occurring from "time to time" in the BBA colonies in the Falklands. Yet, such events have never been quantitatively described in any detail.

(a)

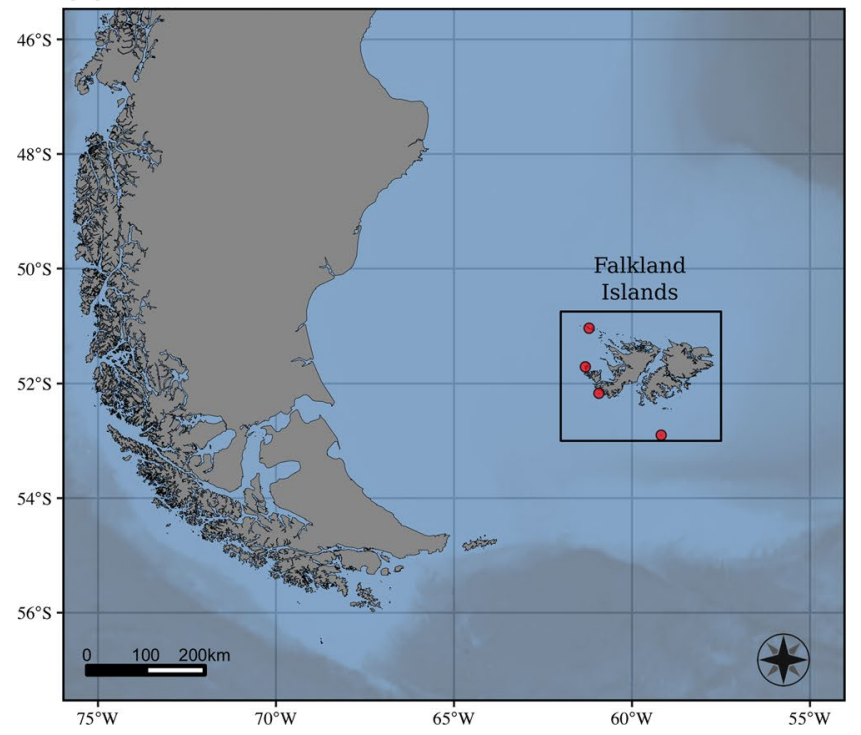

In this research, we investigate the spatial and temporal patterns of mortality not caused by predation in BBA chicks across multiple study seasons and in multiple colonies. In particular, the objectives of this paper are to:

(1) Describe the variability of BBA nestling mortality events across multiple breeding seasons and in different colonies, and investigate their spatio-temporal patterns.

(2) Uncover whether these events are clustered in space and time and quantify the main variables determining their occurrence.

\section{Materials and methods}

\section{Study area and study species}

Fieldwork was conducted mainly at the Settlement rookery $\left(51^{\circ} 43^{\prime} \mathrm{S}, 61^{\circ} 17^{\prime} \mathrm{W}\right)$, New Island (Fig. 1), where an ongoing longitudinal monitoring programme has been carried out since the Austral summers of 2003/04. In this study, we analyse data from the $2004 / 05$ to $2009 / 10,2018 / 19$ and 2019/20 breeding seasons, when the daily monitoring covered the whole duration of brooding. BBA nest colonially both on coastal cliffs and on clearings amongst tussock grass Poa flabellata. Approximately 14,500 BBA pairs breed on New Island, of which more than 1500 nest in the Settlement rookery (Wolfaardt 2013). Complementary work was done at: Steeple Jason $\left(51^{\circ} 19^{\prime} \mathrm{S}, 61^{\circ} 13^{\prime} \mathrm{W}\right)$ during the $2011 / 12$ breeding season; Beauchene $\left(52^{\circ} 54^{\prime} \mathrm{S}, 59^{\circ} 10^{\prime} \mathrm{W}\right)$ and Bird Island $\left(52^{\circ} 10^{\prime} \mathrm{S}, 60^{\circ} 55^{\prime} \mathrm{W}\right)$, during the $2015 / 16$

(b)

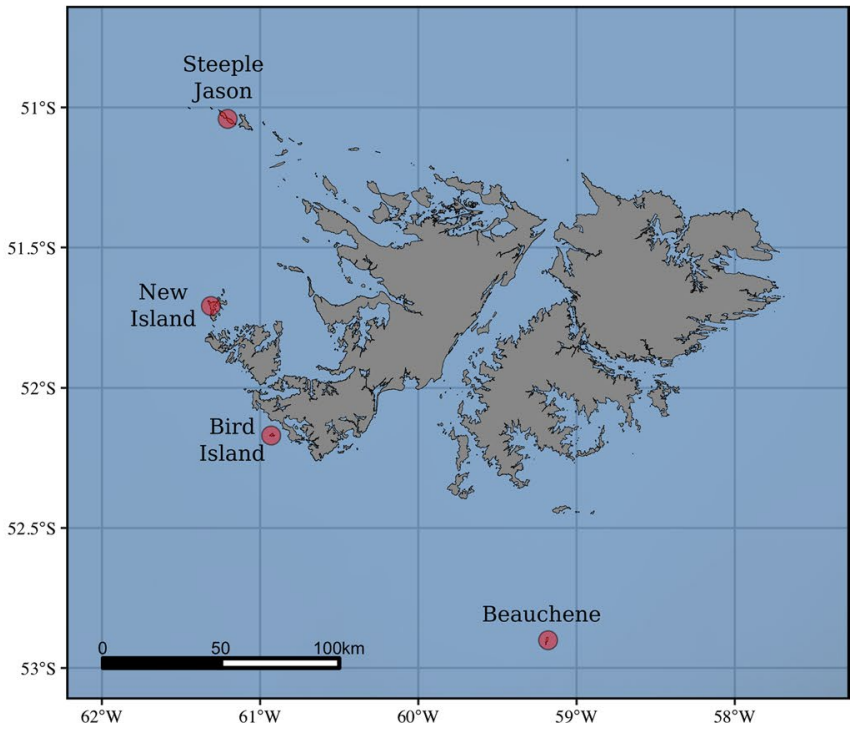

Fig. 1 a Map of the southwest Atlantic Ocean, with the rectangle indicating the location of the Falkland Islands. b Finer-scale map showing the locations of our study sites (the colonies of Steeple Jason, New Island, Bird Island and Beauchene, indicated by red dots) in the Falkland Islands 
season (Fig. 1). Steeple Jason and Beauchene are the largest BBA colonies in the world, with approximately 200,000 and 140,000 breeding pairs, respectively. All three sites, particularly Beauchene, are uninhabited and experience a very limited anthropogenic disturbance. Beauchene and Bird Island have never had any farming or grazing, or any introduced mammals, with human utilization being restricted to short trips to capture seals and penguins, mostly in the eighteenth and nineteenth centuries.

\section{Breeding success and chick survival}

On New Island, we studied three BBA sub-colonies (A, B and $\mathrm{C})$ where all nests are individually marked (148-215 nests altogether annually between 2004/05-2019/20: 34-52 in sub-colony A; 33-44 in B; and 74-119 in C). Each subcolony is located ca. $80 \mathrm{~m}$ from the other two. The status of the nest contents was verified on a daily basis for all nests from the date of laying, through the hatching period (midDecember) and until the end of the brooding period (January), and then weekly until the end of February. A chick alive by the end of February was considered fledged, as mortality (all factors combined, including predation) after this period is typically very low. Albatross chicks were weighed when 58 and 60 days old (for the analyses we used an estimate of the mass at 59 days old, calculated as the mean value between the 58 and 60 days measurements) to produce an indicator of annual food availability (Cairns 1992; Lyons and Roby 2011). On Steeple Jason, Beauchene and Bird Island, linear transects were established crossing breeding colonies, scattered all over the island, and contents of all nests (empty or with a live or dead chick) within ca. $1.5 \mathrm{~m}$ from each transect were sequentially noted down. On Steeple Jason, the work took place on the 25th of December 2011 and 2nd of January 2012; on Beauchene on the 5th of January 2016; on Bird Island on the 3rd of January 2016.

\section{Mortality in the nest}

We restricted the study of chick mortality to the brooding period because after the chick is left alone for the first time, the causes of mortality are difficult or impossible to determine as predation or scavenging might follow quickly. When daily monitoring the nests, we took note of whether a chick was visibly weak or showed any symptoms of ill-health and, whenever a chick was found dead in the nest, the possible causes were investigated. If a chick was not found in the nest, the mortality was attributed to predation events. While this conservative approach is likely to underestimate the number of chicks dying due to causes other than predation, it ensures that the cases recorded as unrelated to predation were classified correctly.
We used binomial generalised linear models (GLMs) to test whether the variability in the proportion of chicks dead in each sub-colony was captured by the following explanatory variables: sub-colonies, years and the interaction between the two. Using negative binomial GLMs, we investigated whether the variability in age at death was explained by sub-colonies, years and their interaction. For both modelling approaches, the best models were selected based on AIC (Akaike 1998).

\section{Spatio-temporal aggregation of mortality}

The mortality events taken into consideration in the following analyses are those not caused by predation. To have a minimum number of death cases ensuring statistical power, we carried out fine-scale spatial and spatio-temporal analyses in years where, within a sub-colony, at least $20 \%$ of the chicks died of causes other than predation (Fig. 2a).

Between the 2003/04 and 2008/09 seasons, all nests of the three sub-colonies studied in New Island were mapped as a lattice by measuring the distance between the centre of each nest and several neighbours (to the nearest $5 \mathrm{~cm}$ ). All sub-colonies lye in a relatively flat area (albeit slightly inclined) and their overall size is less than $25 \mathrm{~m}$ in diameter, so spatial deformations were overall very small. For those seasons, we investigated whether the deaths in our sub-colonies were spatially autocorrelated using Moran's $I$ (Moran 1950), testing the null hypothesis that each case was spatially independent from each other. Moran's I statistical significance (at $0.05 p$ value) was assessed by a Monte Carlo test using 1000 simulations. On Steeple Jason, Beauchene and Bird Island, we used the Wald-Wolfowitz Runs Test for Randomness to check whether the chicks observed dead in the nests occurred in clusters along the transects.

To analyse the spatio-temporal structure of the mortality events, we used cluster and network analysis. Between 2003/04 and 2008/09 (for which explicit spatial data was available), the existence of spatio-temporal clustering was assessed in each sub-colony and year using Gaussian-mixture models (GMMs) and an ad-hoc epidemiological network-based analysis (Cori et al. 2018). To undertake the GMMs clustering, we extracted each observation's spatial coordinates and temporal distance since the first mortality event. We then standardised the variables and clustered the data using GMMs from the mclust package (Scrucca et al. 2016) in R (R Core Team 2019). The best model and the optimal number of clusters were chosen based on BIC (Schwarz 1978). To perform the network analysis, we computed two euclidean distance matrices between nests, quantifying the spatial and temporal (in metres and days, respectively) distances between dead chicks. The matrices were used to build a spatial and a temporal network, in which the nodes represented the nests and the edges length reflected 
(a)

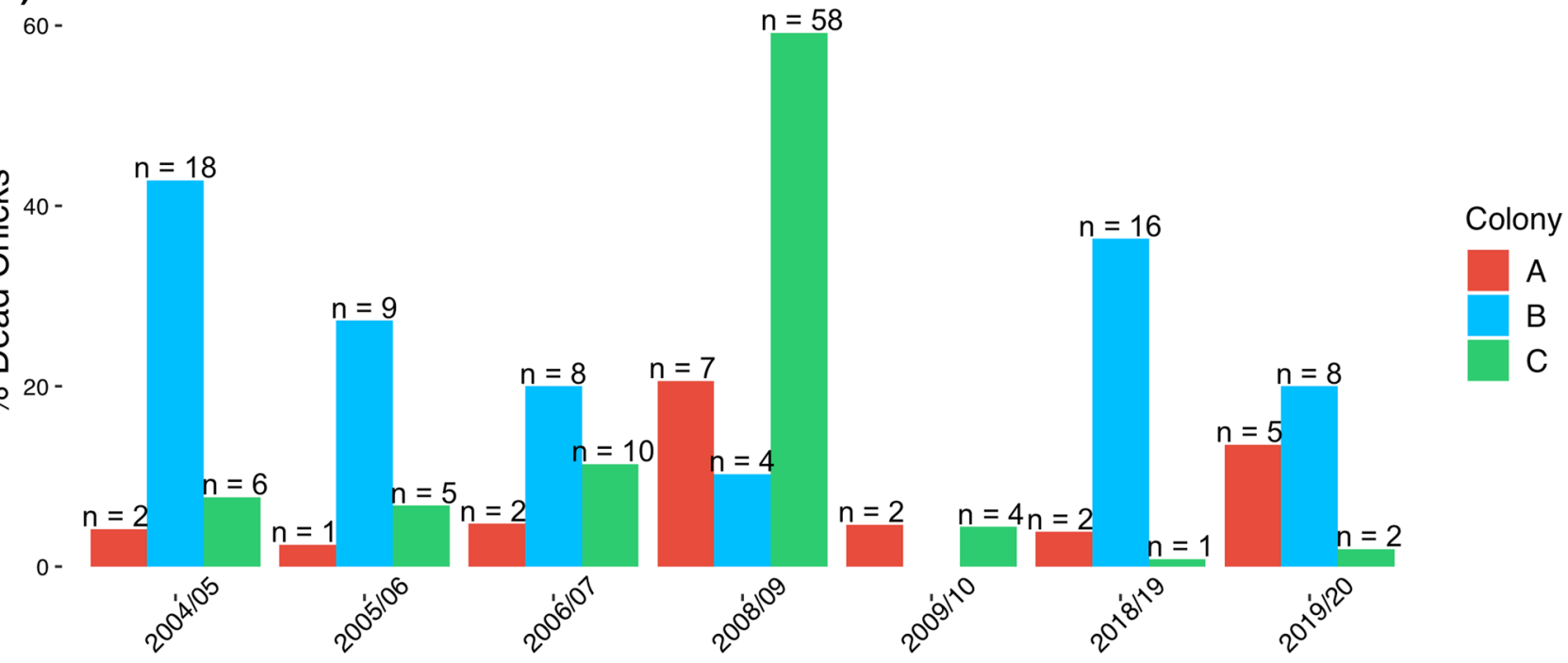

\section{Season}

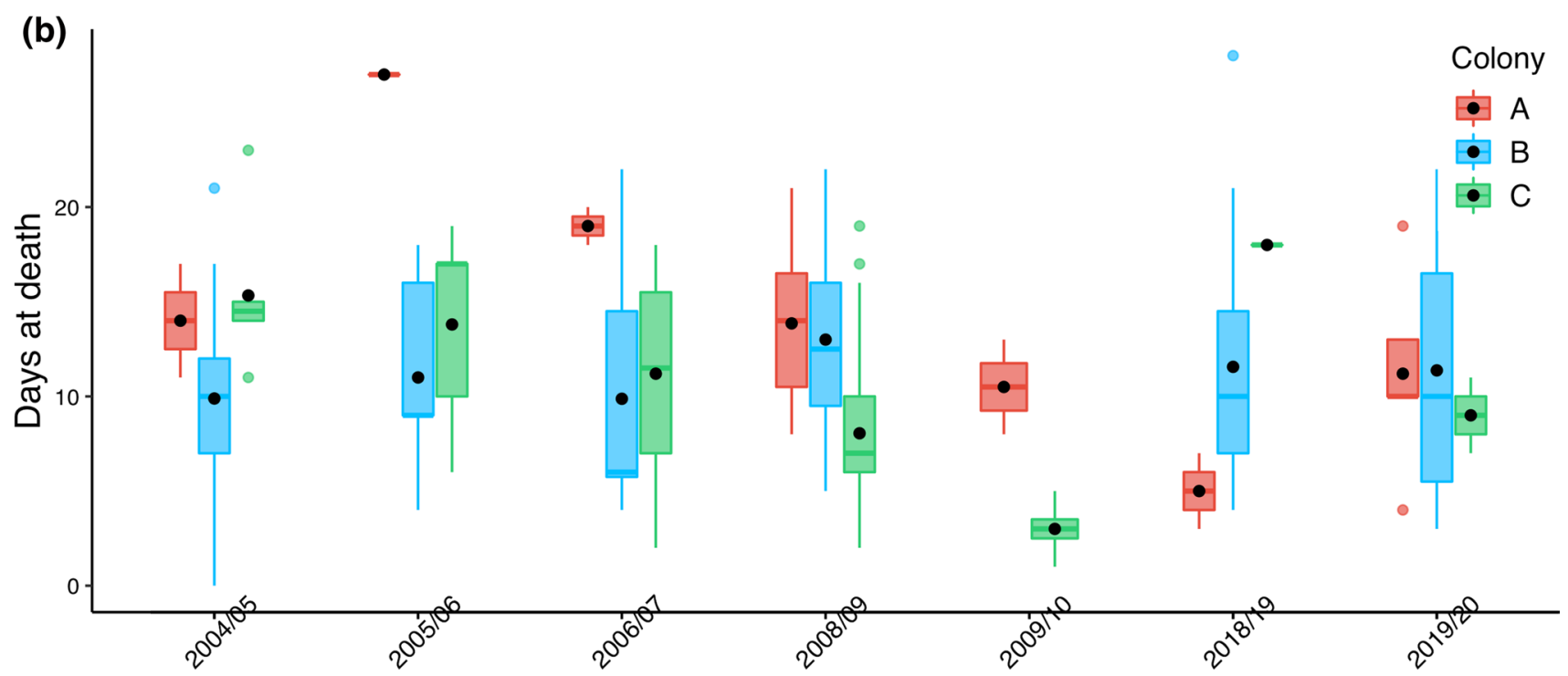

\section{Season}

Fig. 2 a For each year and each sub-colony, the barplot shows the percentage of chicks that died due to causes other than predation. On top of each bar, the respective sub-colony sample size is specified. b

the spatial and temporal distance, respectively. The networks were then trimmed, disconnecting nodes separated by a spatial (5-m) and temporal (7-days) threshold after which the mortality events were assumed not to be directly connected to each other. Finally, we identified the spatio-temporal mortality clusters by overlapping the trimmed networks and retaining the connections between nodes that were consistent in both graphs. For each cluster identified by each methodology, we calculated the average and maximum spatial and
Boxplot showing the age (days) at death (median, 0.25 and 0.75 quantile) in each sub-colony, over the study seasons. The black circle represents the mean and the vertical "whisker" line the range

temporal distance between each mortality case and its four closest neighbours in that cluster.

\section{Effect of spatial and temporal scale and age of chick on mortality}

Based on the classification yielded by the previous analytical step, we calculated for each cluster: the temporal lag between each mortality event and the first mortality event 
in that cluster; and the spatial distance between each nest with mortality and the nest where the first mortality event occurred. Using a negative-binomial GLM, we investigated whether the temporal lag of each case from the first one (i.e. the temporal progression of the mortality events) was explained by the spatial distance between them.

Lastly, we focussed our analysis on the events that occurred in sub-colony $\mathrm{C}$ in 2008/09, when approx. $60 \%$ of the chicks died due to causes other than predation. We investigated whether the probability of a chick dying on the nest was affected by the nestling age, by the distance from the closest chick that died and by the interaction between these two variables. We constructed a dataset in which the status $(0=$ alive, $1=$ dead $)$ of every nest was recorded at every sampling occasion-with the sampling occasions comprising each day that at least one death occurred. For all chicks, at each sampling occasion, we calculated: the age on the specific date; and the distance from the closest nest where a chick died previously. After the chick had died, its status was not recorded in subsequent visits. The constructed dataset was analysed using binomial-based generalised additive mixed models (GAMMs), in which the binary response (alive/dead) was modelled as a function of age (tested both as linear and as smooth term), distance from closest mortality and the interaction between the two. To account for the dependency between observations collected on the same nestling, each chick was included as random effect. All explanatory variables entered the model as cubic regression splines with shrinkage in order to prevent overfitting. The best variables to retain in the GAMM were selected based on AIC.

\section{Results}

\section{Mortality in the nest}

Across all breeding seasons, in all BBA colonies in this study, most chicks that were found dead in the nest (many still guarded by one adult) consistently showed the following symptoms before dying: swollen gape flanges, serous conjunctival discharge, swollen and purplish coloured inter-phalangeal joints and a lower carriage of the neck, with apparent difficulty in lifting the head up. Most of them were visibly leaner than other chicks of the same age. These symptoms, which usually resulted in the death of the chick within ca. a week of their appearance, were mostly observed when chicks were one to two weeks old. Although not systematically recorded, we only rarely saw chicks with these clinical signs after the period of brood-guarding, and seldom recorded any mortality.

On New Island, mortality events of BBA nestlings not caused by predation showed a high variability across years, both in terms of the numbers of deceased chicks and of the sub-colonies that suffered the highest losses (Fig. 2a). Overall, pooling the data from all sub-colonies, the levels of mortality had a variable impact on the breeding success: in different years, from 3.5 up to $40.4 \%$ of all chicks died during brooding due to causes unrelated to predation. In seven instances distributed across six breeding seasons (sub-colony A: 2008/09; sub-colony B: 2004/05, 2005/06, 2006/07, 2018/19, 2019/20; sub-colony C: 2008/09), at least $20 \%$ of all hatched chicks died due to causes other than predation. In 2008/09, as much as 69 of the 81 (i.e. $85 \%$ ) deceased chicks in all colonies were not killed by predators (Fig. 2a).

The binomial GLM comprising the interaction between year and sub-colony was selected based on AIC, indicating that the mortality levels in different sub-colonies varied across different years (clearly seen in Fig. 2a). No significant relationship was found between the annual prevalence of mortality during brooding and apparent annual availability of food, indicated by the mean mass of the chicks at 59 days of age (Pearson's correlation, $r_{5}=-0.074, p=0.94$ ).

The mean age at death (all years and sub-colonies combined) was 10.3 days $\pm 5.5(n=170)$. The variability in the age of the chicks found dead in the nest (Fig. 2b) was explained by the interaction between sub-colony and year in the negative binomial GLM selected based on AIC, suggesting that the age at death varied in different sub-colonies across the different study seasons.

The numbers of dead chicks observed along the transects on Steeple Jason, Beauchene and Bird Island are considerable underestimates of chick mortality, as many dead chicks would have disappeared within a few days of dying. The transects carried out on Steeple Jason during the 2011/12 season revealed that, overall, $12.5 \%$ of all chicks seen were dead ( $n=4,554$ nests with chicks, alive or dead) and that $61.9 \%$ of all nests $(n=6,441)$ contained a live chick. The transects carried out on Beauchene and Bird Island during the 2015/16 breeding season showed that 2.8\% $(n=605$ nests with chicks, alive or dead) and 3.2\% $(n=314)$ chicks were dead, respectively. In total, 68.4\% $(n=860)$ and $53.7 \%$ $(n=566)$ of all nests had a live chick in Beauchene and Bird Island, respectively.

\section{Spatio-temporal aggregation of mortality}

The calculated Moran's $I$ indicated spatial clustering of mortality in 2008/09 within sub-colony A (Moran's $I=0.37$, $p=0.001$ ) and in sub-colony C (Moran's $I=0.17, p=0.001$ ), while near-significant clustering was found in 2006/07 in sub-colony B (Moran's $I=0.10, p=0.066$ ). We found no clustered pattern in the two other situations, both in (the much smaller) sub-colony B (in 2004/05: Moran's $I=-0.06$, $p=0.594$; in 2005/06: Moran's $I=-0.08, p=0.605$ ), likely due to small sample sizes. 
The results from the Wald-Wolfowitz Runs Test for Randomness for both Steeple Jason (both months) and Beauchene showed that nests with dead chicks were spatially aggregated ( $p<0.0001$ on both occasions) but not on Bird Island ( $p=0.657$ ). The distribution of nests with live chicks was also aggregated (Steeple Jason, $p<0.0001$; Beauchene, $p<0.001$; Bird Island, $p<0.0001$ ).

The selected GMMs-based and network-based clusters were identified (Fig. 3a). The average and maximum spatial and temporal distance from closest neighbours produced consistent estimates under the two different methodologies (Fig. 3b). For the GMMs-based clusters, they were equal to 2.6-3.3 m (average-maximum estimates, respectively) and

(a)
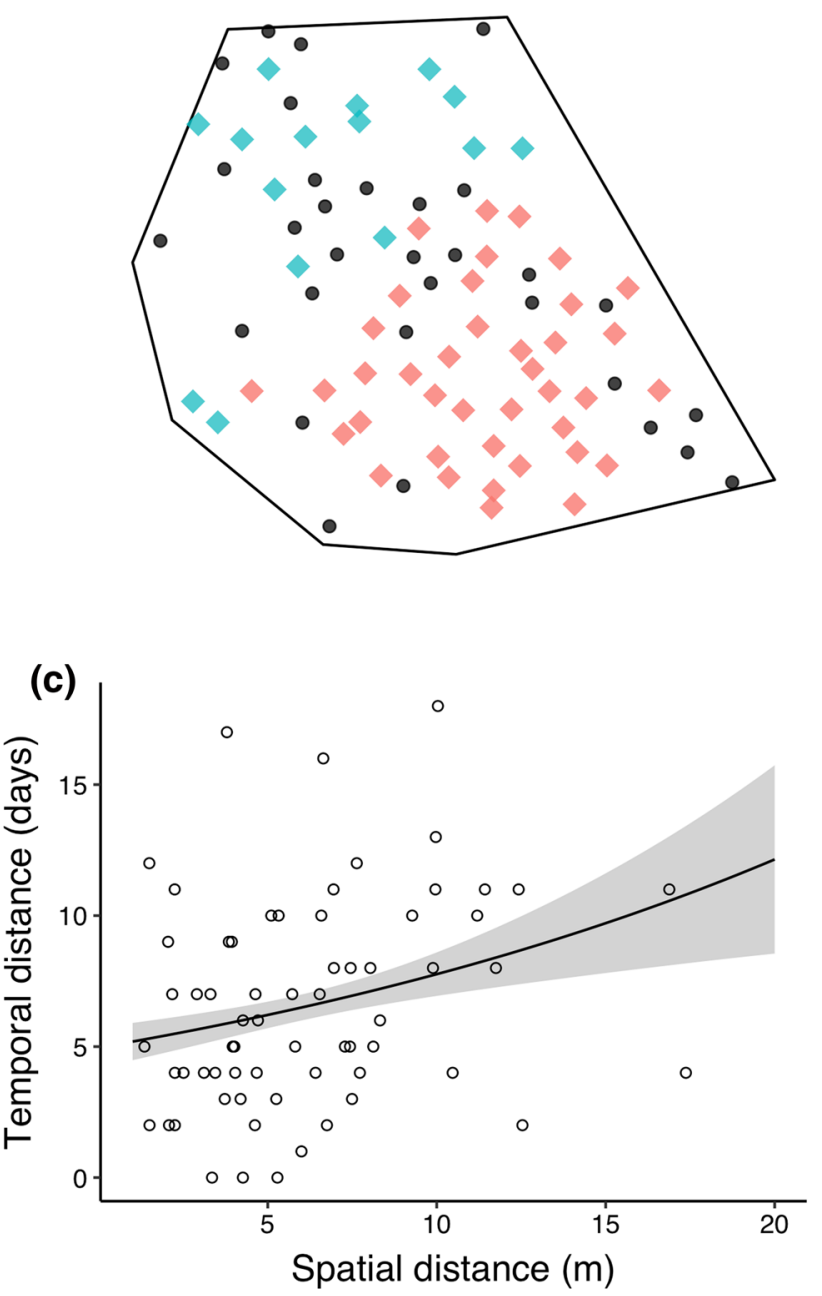

Fig. 3 a Example of cluster analysis based on Gaussian-mixture models (GMM) for sub-colony C in 2008/2009. The circles represent nests with chicks surviving to fledging or that died due to predation; the rhombuses depict nests that experienced mortality events not caused by predation, with different colours representing different clusters. b The average and maximum spatial and temporal distance between each nest in that cluster and its four closest neighbours, calculated for both GMM and network-based clusters. $\mathbf{c}$ and $\mathbf{d}$ Results

4.0-6.5 days, whereas for the network-based clusters, they were equal to $2.4-3.1 \mathrm{~m}$ and 5.0-8.4 days.

\section{Effect of spatial and temporal scale and age of chick on mortality}

In each cluster, regardless of the methodology used for the cluster classification, the spatial distance between each nest and the nest where the first chick died was retained as a significant explanatory variable determining the temporal progression of the mortality events (GMMbased: $z$-value $=2.124, d f=1, p=0.037$; network-based: $z$-value $=3.156, d f=1, p=0.002)$. In the GMM-based

(b)
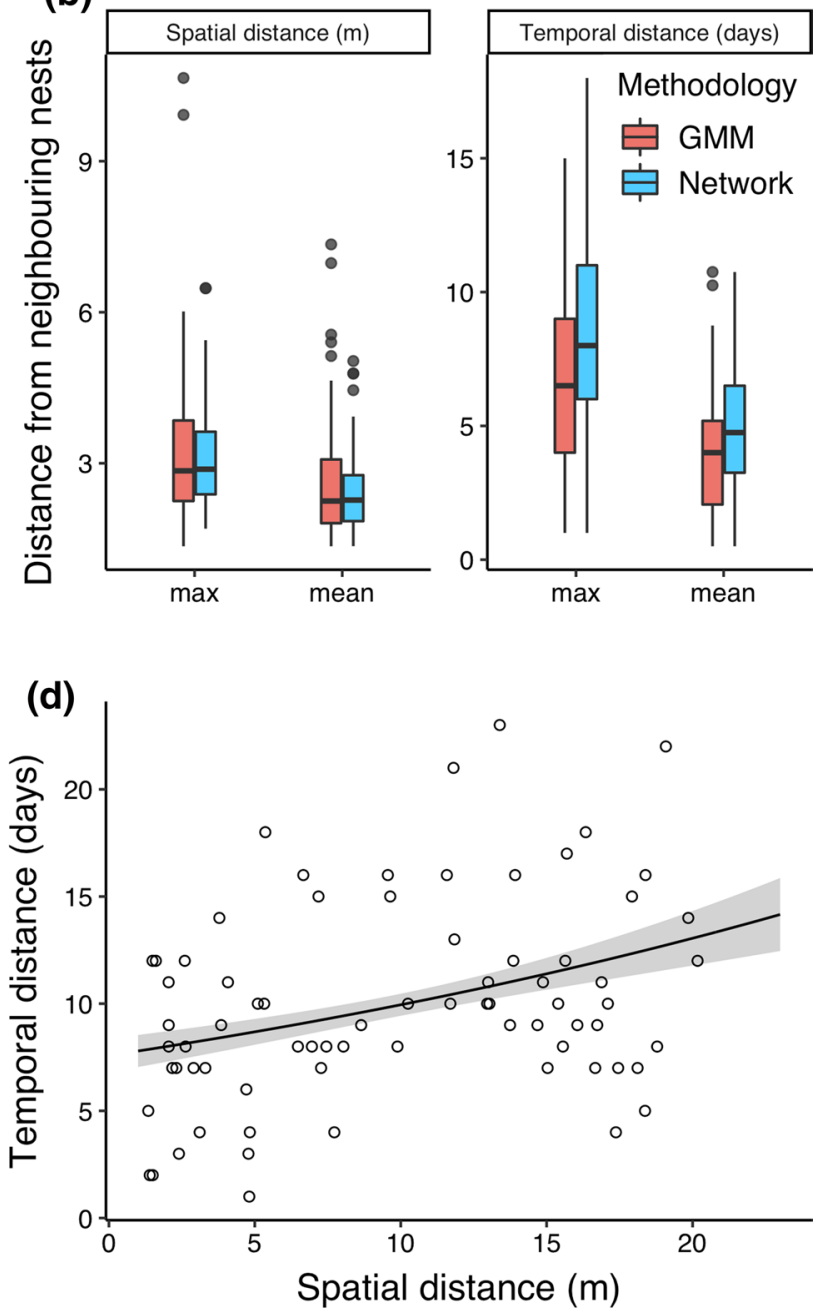

of the negative binomial generalised linear model based on the output from GMM-based and network-based clusters, respectively. On the $y$-axis, the temporal lag between each mortality event and the first mortality event in that cluster; on the $x$-axis, the spatial distance between each nest with mortality and the nest where the first mortality event occurred. The shaded areas represent the $95 \%$ confidence intervals and the points are the observed data 
(Fig. 3c) and network-based classification (Fig. 3d), nests more distant from the mortality starting point took longer to experience mortality events than nests closer to the starting point. More specifically, chicks in nests located $10 \mathrm{~m}$ away from the mortality starting point were predicted to die 2.6 and 2.2 days later than chicks that were just $1 \mathrm{~m}$ away, respectively.

In the largest mortality instance recorded in our study (sub-colony C, 2008/09 breeding season), both chick age (as linear term) and distance from closest mortality event (as smooth term), but not their interaction, were retained as significant explanatory variables affecting the probability of a chick dying. The probability of dying increased as chicks became older and was highest for chicks in close proximity to a nest where a chick had already died (Fig. 4).

\section{Discussion}

\section{Variability of nestling mortality}

Between the 2003/04 and 2019/20 breeding seasons, we found variable levels of BBA chick mortality during brooding. In the study plots on New Island, these mortality events decreased the overall breeding success by a minimum of $3.5 \%$ and a maximum of over $40 \%$, affecting different

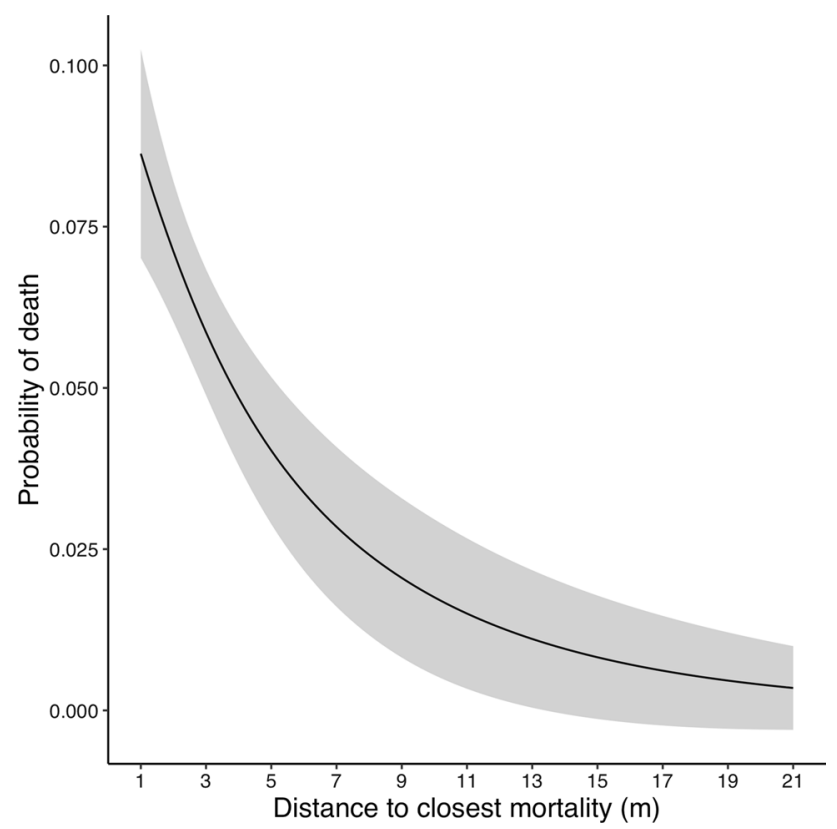

Fig. 4 Results of the generalised additive mixed model (GAMM) for sub-colony $\mathrm{C}$ in 2008/09, showing how the probability of death for a 7-day old chick (i.e. the median age at death in sub-colony $\mathrm{C}$ in 2008/09, chosen for visualisation purposes) is affected by distance from the closest chick mortality event. The shaded areas are the $95 \%$ confidence intervals sub-colonies to a variable extent in different years. On Steeple Jason, Beauchene and Bird Island, a minimum of 2.8\% to a maximum of $12.5 \%$ of chicks were found dead in the nest on a single visit (which must be a considerable underestimate of the real number of deaths, see "Results"sect. above). The prevalence of mortality across years did not correlate with mean chick body mass at 59 days of age, suggesting that the variability in the mortality levels was not explained by malnutrition and insufficient food. Additionally, the results on clustered mortality patterns do not fit within malnutrition as a primary cause of death, as in that case we would expect dead chicks to be evenly distributed throughout the breeding colonies.

\section{Spatio-temporal aggregation of mortality}

On all islands, our results provide evidence of spatial aggregation of mortality. The lack of structuring detected on New Island in sub-colony B might be due to the small area of the sub-colony (ca. $150 \mathrm{~m}^{\wedge} 2$, i.e. $\sim 80 \%$ and $\sim 40 \%$ of the area of sub-colony $\mathrm{A}$ and $\mathrm{C}$, respectively) and to small sample sizes. On Bird Island, while no spatial clustering was detected for the chicks found dead on the nest, there was strong evidence of clustering of live chicks, meaning that the nests not inhabited by live chicks (comprising both dead chicks and empty nests, many of which might have had dead chicks removed) were also clustered. In years when more than $20 \%$ of the chicks died for causes unrelated to predation, the finer-scale analysis of the New Islands study plots revealed further insight into the patchy structure of the chick mortality events in space and time. Our results show that, within the identified clusters, the chicks closer to the first mortality event were more likely to die before the nestlings more distant to the mortality starting point. Furthermore, the probability of a chick dying increased as its age also increased, and was highest for chicks occupying nests in proximity of a nest where a chick had died previously.

\section{The potential role of an unidentified infectious disease}

While the identification of the specific agent causing the described mortality was beyond the scope of this paper, our results, providing robust evidence of spatio-temporally clustered mortality patterns, are strongly suggestive of and are consistent with the activity of an infectious disease (Carpenter 2001). Further evidence for the role of an infectious disease is provided by the different susceptibility of chicks of different ages, with chicks being more likely to die as they get older, mostly during their first two weeks of life (mean age at death equal to 10.3 days $\pm 5.5(n=170))$. Given that we mostly detected mortality up to the end of the brooding stage, the spatio-temporal clustering of mortality might have 
been partly explained by coordination of hatching: however, this was not the case, as we did not detect any significant spatio-temporal clustered patterns -using inhomogeneous space-time $K$ functions (Gabriel and Diggle 2009; result not shown in the text). Together with the spatio-temporal patterns of mortality, the prevalence of an infectious disease with a potentially common aetiology is further suggested by the common symptomatology (described above) exhibited on the days prior to death by a large proportion of chicks.

Previous research has shown that individual seabirds of different quality (with differential foraging ability or capacity of provisioning) may distribute differentially within breeding colonies (Coulson 1968), with higher quality birds occupying the best areas, which might ultimately result into aggregated patterns of chick mortality. However, this does not seem to hold true in our case for the following reasons. Firstly, there is no evidence that albatross colonies are spatially structured on the basis of quality factors, such as age or breeding experience. Secondly, the variable prevalence of mortality in different sub-colonies from one year to the next strongly argues against the possibility that the observed patterns might arise due to the conditions of the colony, or of the birds that inhabit them. In fact, the higher or lower quality of some nesting areas within the colonies, i.e. some sites might be more exposed to physical agents such as wind (which, in any case, should not constitute an issue during brooding given the buffering effect of the parent), cannot explain the variability in mortality prevalence in the same sub-colonies in different years. Additionally, in the vast majority of cases, albatrosses' extreme nest fidelity and high adult survival rates means that the contrasting mortality patterns were recorded even if it was mostly the same birds nesting in the same sub-colonies. Thirdly, as egg laying date and individual quality are not related in albatrosses (Catry et al. 2010), a hypothetical structuring of the colonies based on the birds' quality could only explain the spatial, but not the temporal synchrony of the mortality events.

Seabirds-albatrosses and penguins in particularare particularly affected by recurrent disease outbreaks (Weimerskirch 2004; Dias et al. 2019), with high population level impacts (Bourret et al. 2018; Uhart et al. 2018). Some of the life history traits common to many seabird species, such as dense colonial nesting habits, a prolonged breeding period and extreme philopatry, make them potentially very vulnerable to disease threats, allowing pathogens to spread quickly during the breeding season and to persist for prolonged periods. Additionally, due to growing human trade and tourism, the exposure of immunologically naïve seabirds (typically nesting on remote and isolated areas) to new pathogens might be increasing in the short term (Phillips et al. 2016). The variability and the comparatively smaller scale of the mortality events described here, compared for instance to the magnitude of the die-offs caused by avian pox and cholera (Woods et al. 2009), the observed symptomatic history and the vast majority of the cases occurring when the chicks are one to two weeks old, do not seem to match the seabird disease outbreaks described in the literature (Uhart et al. 2018). Yet, the consistent results obtained for New Island, Steeple Jason, Beauchene and Bird Island, with dead chicks showing similar symptoms, together with the possibly related reports from Tickell and Pinder (1975), suggest that the occurrence of these mortality events might be historically widespread in the BBA colonies in the Falklands, both in areas visited by humans and in those that are not, potentially sharing a common aetiology.

Various diseases, disease causing agents and potential reservoirs or vectors have been described for albatrosses. For instance, Pasteurella multocida, the bacteria responsible for recurrent avian cholera outbreaks over the past decades (Leotta et al. 2006), was linked to poultry and human dispersion even in remote areas of Antarctica (Woods et al. 2009). During the avian cholera outbreaks on Amsterdam Island affecting the population of Indian yellow-nosed albatrosses (Thalassarche carteri), scavenging skuas seemed to play an important role in the dispersal of $P$. multocida between colonies (Gamble et al. 2020). The bacteria Erysipelothrix rhusiopathiae causing pathologies in Indian yellow-nosed albatrosses might be naturally present in fish or in introduced pigs (Jaeger et al. 2015; Weimerskirch 2016). In the BBA population in South Georgia, migrating species, scavengers and human visitors or researchers seemed to contribute to the transmission of the bacteria Salmonella newport (Palmgren et al. 2000). The DNA of Borrelia garinii, responsible for bacterial infections in BBA, was found in Ixodes uriae ticks (Olsén et al. 1995). In fact, tick infestation was found to have direct repercussions on colonial seabirds population dynamics (Boulinier and Danchin 1996), inducing nest or even colony abandonment (Duffy 1983), affecting nestlings' phisiological parameters (Ferrer and Morandini 2019) and having high potential for the transmission of pathogens such as the bacteria Borrelia burdogferi (Olsén et al. 1993) and viruses such as Xavivirus, Flaviviruses, Orbivirus, Phlebovirus or Nairovirus (Nuttall 1984; Major et al. 2009). Viral pathogens in shy albatrosses (Thalassarche cauta) include avian Paramyxovirus and the recently discovered zoonotic Hunter Island Group (HIGV) Phlebovirus (Wang et al. 2014), which may be spread by different possible vectors, such as phlebotomine sandflies (Phlebotomus spp.), mosquitoes and ticks. The Avipoxvirus isolates obtained from BBA in the Falklands (Munro 2007) show phylogenetic proximity with Poxviridae viruses found in penguins in Argentina, suggesting a widespread and long-term circulation of these pathogens in the region.

Given the unidentified nature of the potential pathogenic agent involved, it is not possible to exclude the influence of human activity on the mortality events documented 
in this study. On New Island, sealing, whaling and farming took place in the eighteenth, nineteenth and twentieth century and currently the island is visited by researchers and tourists. However, on Steeple Jason, Beauchene and Bird Island, the potential influence of humans and anthropogenic disturbance on the BBA colonies is extremely limited. Beauchene and Bird Island, in particular, have never experienced any farming or grazing, and did not suffer from the introduction of any mammal species or any use for tourist purposes; they were the object of brief visits until no later than the first half of the twentieth century to hunt penguins and seals, and currently only receive a small number of visits from researchers. Thus, even if historically humans might have been responsible for the introduction of this pathology in the archipelago, its transmission to the remote BBA colonies may have occurred indirectly by way of other vectors.

In conclusion, the cause and means of contagion of this disease-related mortality events remain unknown and further investigations would benefit from the examinations of samples of organs from freshly dead chicks in the field. Moreover, the analysis of antibodies in plasma samples collected from BBA (Gamble et al. 2019) or from the scavenging and predatory skuas (Gamble et al. 2020) might reveal crucial insight into the exposure of the avian community to pathogens. A thorough understanding of the causes underpinning the occurrence and the magnitude of these events is of pivotal importance, particularly so in the Falklands, which host more than $70 \%$ of the BBA world population. The prevalence of this unidentified infectious disease is a potentially important factor driving the variability in nestling mortality and, in some seasons, had a substantial impact on the BBA breeding success, being yet another identified threat for this species. As almost all albatross species are currently threatened, and since the prevalence and impact of diseases affecting these birds can be modulated by climate change and by the human-related spread of pathogens, we believe that filling important gaps in the current coverage of epidemiological research and understanding the implications for conservation and management is a pressing conservation priority.

Acknowledgements This work would not have been possible without the help and support of the late Ian Strange, who created the conditions for researchers to work on New Island and who we remember with much gratitude and admiration. Thanks to Maria and Georgina Strange, Dan Birch, Riek van Noordwijk, Nina Dehnhard, Ana Campos, Teresa Catry, Miguel Lecoq, Ana Almeida, Amanda Kuepfer, Caitlin Frankish, Natasha Gillies and Martin Beal for their help. We are grateful to Katie Hampson for her helpful insight into quantitative epidemiological analysis. The New Island Conservation Trust supported field studies on New Island through the supply of research facilities. Thanks to Miguel Ferrer and two anonymous referees for their helpful comments on a previous version of this manuscript.
Author contributions PC and JPG designed the research; FV, PC, JPG and RM performed the research and conducted field-work; FV developed the analytical methodology; FV wrote the paper. All authors contributed critically to the drafts and gave final approval for publication.

Funding This work was funded by the Fundação para a Ciência e a Tecnologia (FCT, Portugal) through the projects: UIDB/04292/2020 and UIDP/04292/2020, granted to MARE; UIDB/50017/2020 and UIDP/50017/2020, granted to CESAM. The Falkland Islands Government provided formal permits and funding through the Environmental Studies Budget.

Data availability The dataset presented here is available for download as electronic supplementary material at https://figshare.com/authors/ Francesco_Ventura/7066628

Code availability The supporting $\mathrm{R}$ scripts to reproduce the analysis are available for download as electronic supplementary material at https:// figshare.com/authors/Francesco_Ventura/7066628

\section{Compliance with ethical standards}

Conflicts of interest The authors declare that they have no conflict of interest.

\section{References}

Akaike H (1998) A new look at the statistical model identification. In: Parzen E, Tanabe K, Kitagawa G (eds) Selected papers of hirotugu akaike. Springer, New York, NY, pp 215-222

Birdlife International (2018a) State of the World's birds: taking the pulse of the planet. BirdLife International, Cambridge, UK

Birdlife International (2018b) Thalassarche melanophris. IUCN Red List Threat Species 2018https://doi.org/10.2305/IUCN. UK.2018-2.RLTS.T22698375A132643647.en

Boulinier T, Danchin E (1996) Population trends in Kittiwake Rissa tridactyla colonies in relation to tick infestation. Ibis (Lond 1859) 138:326-334. https://doi.org/10.1111/j.1474-919X.1996.tb043 45.x

Bourret V, Gamble A, Tornos J et al (2018) Vaccination protects endangered albatross chicks against avian cholera. Conserv Lett 11:1-7. https://doi.org/10.1111/conl.12443

Cairns DK (1988) Seabirds as Indicators of Marine Food Supplies. Biol Oceanogr 5:261-271. https://doi.org/10.1080/01965 581.1987 .10749517

Cairns DK (1992) Population regulation of seabird colonies. In: Power DM (ed) Current ornithology. Springer, Boston, MA, pp 37-61

Carpenter TE (2001) Methods to investigate spatial and temporal clustering in veterinary epidemiology. Prev Vet Med 48:303-320. https://doi.org/10.1007/s00421-008-0955-8

Catry P, Phillips RA, Forster IP et al (2010) Brood-guarding duration in black-browed albatrosses Thalassarche melanophris: temporal, geographical and individual variation. J Avian Biol 41:460-469. https://doi.org/10.1111/j.1600-048X.2010.05029.x

Catry P, Forcada J, Almeida A (2011) Demographic parameters of black-browed albatrosses Thalassarche melanophris from the Falkland Islands. Polar Biol 34:1221-1229. https://doi. org/10.1007/s00300-011-0984-3

Cori A, Nouvellet P, Garske T et al (2018) A graph-based evidence synthesis approach to detecting outbreak clusters: an application to dog rabies. PLoS Comput Biol 14:1-22. https://doi.org/10.1371/ journal.pcbi.1006554 
Coulson JC (1968) Differences in the quality of birds nesting in the centre and on the edges of a colony. Nature 217:478-479. https:// doi.org/10.1038/217478a0

Cury PM, Boyd IL, Bonhommeau S et al (2011) Global seabird response to forage fish depletion-one-third for the birds. Science 334:1703-1706. https://doi.org/10.1126/science.1212928

Dias MP, Martin R, Pearmain EJ et al (2019) Threats to seabirds: a global assessment. Biol Conserv 237:525-537. https://doi. org/10.1016/j.biocon.2019.06.033

Duffy DC (1983) The ecology of tick parasitism on densely nesting Peruvian seabirds. Ecology 64:110-119. https://doi. org/10.2307/1937334

Ferrer M, Morandini V (2019) Tick infestations correlates at a Falkland Islands Black-browed Albatross colony. Polar Biol 42:625-631. https://doi.org/10.1007/s00300-018-02445-5

Gabriel E, Diggle PJ (2009) Second-order analysis of inhomogeneous spatio-temporal point process data. Stat Neerl 63:43-51. https:// doi.org/10.1111/j.1467-9574.2008.00407.x

Gamble A, Garnier R, Jaeger A et al (2019) Exposure of breeding albatrosses to the agent of avian cholera: dynamics of antibody levels and ecological implications. Oecologia 189:939-949. https ://doi.org/10.1007/s00442-019-04369-1

Gamble A, Bazire R, Delord K et al (2020) Predator and scavenger movements among and within endangered seabird colonies: Opportunities for pathogen spread. J Appl Ecol 57:367-378. https ://doi.org/10.1111/1365-2664.13531

Jaeger J, Lebarbenchon C, Thiebot JB, et al (2015) Diseases of endangered seabirds on Amsterdam island: tracking etiologic agents and introduction of biosecurity measures. In: Second world seabird conference, Cape Town, South Africa, pp 251-252. https://world seabirdconference.com/wp-content/uploads/2014/02/WSC2-Abstr act-Book_rev.pdf

Leotta GA, Chinen I, Vigo GB et al (2006) Outbreaks of avian cholera in Hope Bay, Antarctica. J Wildl Dis 42:259-270. https://doi. org/10.7589/0090-3558-42.2.259

Lyons DE, Roby DD (2011) Validating growth and development of a seabird as an indicator of food availability: captive-reared Caspian Tern chicks fed ad libitum and restricted diets. J F Ornithol 82:88-100. https://doi.org/10.1111/j.1557-9263.2010.00311.x

Major L, La LM, Slade RW et al (2009) Ticks associated with macquarie island penguins carry arboviruses from four genera. PLoS ONE 4:e4375-e4375. https://doi.org/10.1371/journal.pone.00043 75

Monaghan P (1996) Relevance of the behaviour of seabirds to the conservation of marine environments. Oikos 77:227-237. https://doi. org/10.2307/3546061

Moran PAP (1950) Notes on continuous stochastic phenomena. Biometrika 37:17-23. https://doi.org/10.2307/2332142

Munro G (2007) Outbreak of avian pox virus in gentoo penguins in the Falklands, February 2006. Falklands Conservation, Falkland Islands

Nuttall PA (1984) Tick-borne viruses in seabird colonies. Seabird $7: 31-41$

Olsén B, Jaenson TG, Noppa L et al (1993) A Lyme borreliosis cycle in seabirds and Ixodes uriae ticks. Nature 362:340-342. https:// doi.org/10.1038/362340a0
Olsén B, Duffy DC, Jaenson TG et al (1995) Transhemispheric exchange of Lyme disease spirochetes by seabirds. J Clin Microbiol 33:3270-3274. https://doi.org/10.1128/ JCM.33.12.3270-3274.1995

Palmgren H, McCafferty D, Aspán A et al (2000) Salmonella in SubAntarctica: low heterogeneity in salmonella serotypes in South Georgian Seals and Birds. Epidemiol Infect 125:257-262. https ://doi.org/10.1017/s0950268899004586

Phillips RA, Gales R, Baker GB et al (2016) The conservation status and priorities for albatrosses and large petrels. Biol Conserv 201:169-183. https://doi.org/10.1016/j.biocon.2016.06.017

R Core Team (2019) R: a language and environment for statistical computing. R Foundation for Statistical Computing, Vienna

Schwarz G (1978) Estimating the dimension of a model. Ann Stat 6:461-464. https://doi.org/10.1214/aos/1176344136

Scrucca L, Fop M, Murphy TB, Raftery AE (2016) Mclust 5: clustering, classification and density estimation using Gaussian finite mixture models. R J 8:289-317. https://doi.org/10.32614 /rj-2016-021

Tickell WLN (2000) Albatrosses. Yale University Press, London

Tickell WLN, Pinder R (1975) Breeding biology of black-browed albatross Diomedea melanophris and grey-headed albatross Diomedea chrysostoma at Bird Island, South Georgia. Ibis (Lond 1859) 117:433-451. https://doi.org/10.1111/j.1474-919X.1975.tb042 37. $\mathrm{x}$

Uhart MM, Gallo L, Quintana F (2018) Review of diseases (pathogen isolation, direct recovery and antibodies) in albatrosses and large petrels worldwide. Bird Conserv Int 28:169-196. https://doi. org/10.1017/S0959270916000629

Wang J, Selleck P, Yu M et al (2014) Novel phlebovirus with zoonotic potential isolated from ticks, Australia. Emerg Infect Dis 20:1040 1043. https://doi.org/10.3201/eid2006.140003

Weimerskirch H (2004) Diseases threaten Southern Ocean albatrosses. Polar Biol 27:374-379. https://doi.org/10.1007/s0030 0-004-0600-x

Weimerskirch H (2016) ACAP Priority Population AssessmentIndian yellow nosed albatross at Amsterdam Island (Indian Ocean). In: Third meeting of the Population and Conservation Status Working Group, La Serena, Chile, 5-6 May 2016

Wolfaardt A (2013) An assessment of the population trends and conservation status of Black-browed Albatrosses in the Falkland Islands. In: First meeting of the population and conservation status workinggroup of the agreement on the conservation of albatrosses and petrels. La Rochelle, France, 29-30 April 2013

Woods R, Jones HI, Watts J et al (2009) Diseases of Antarctic seabirds. In: Kerry KR, Riddle M (eds) Health of Antarctic wildlife: a challenge for science and policy. Springer, Berlin, pp 35-55

Publisher's Note Springer Nature remains neutral with regard to jurisdictional claims in published maps and institutional affiliations. 